\title{
PULMONARY AGENESIS AND HYPOPLASIA
}

\author{
BY \\ C. .ELAINE FIELD, M.D., M.R.C.P. \\ First Assistant to the Children's Department, University College Hospital, and E.M.S.
Medical Officer
}

In recent years the more frequent use of x-rays has revealed various congenital abnormalities of the lungs which had formerly passed undetected during life, since the clinical signs and symptoms may be minimal. An attempt is made here to elucidate the different pictures which may be seen in varying degrees of underdevelopment of the lungs.

For clarity of description the following nomenclature is based on Schneider's (1912) classification:

AgENESIS of a lung, where there is complete absence of lung and bronchus.

APLASIA of a lung, where there is a rudimentary bronchus and no pulmonary alveolar tissue.

HYPOPLASIA of a lung or part of a lung, where the alveolar tissue is underdeveloped.

The number of cases so far reported in the literature is about fifty. Hurwitz and Stephens (1937) review thirty-four cases and Deweese and Howard (1944) make the list up to forty-four. The majority of these recorded cases are of the first type, viz. agenesis, or complete absence of a lung, more commonly the left lung. The pleura may be partially or completely absent; the former is more common, the pleura then containing the displaced heart and mediastinal structures with some excess fluid. The pulmonary blood-vessels of the affected side are usually absent. The remaining casereports describe severe degrees of aplasia or hypoplasia with practically no functional lung tissue; it is therefore of interest to report cases 4 and 5 where there is only partial underdevelopment of one lung associated with an anatomical abnormality of the bronchial tree, all of which complex appears to be a permanent abnormality. In contrast, cases 6 to 11 show a similar underdevelopment of one lung at birth, but the condition slowly readjusts itself to normal in two to three years.

The majority of recorded cases of maldevelopment have been in young infants diagnosed shortly before death or at autopsy, but the condition is compatible with a full span of life, as in a female who lived to seventy-two years. The sex incidence has been about equal. The common association of other congenital abnormalities in the chest or elsewhere is noteworthy. Symptoms varied from case to case and included cyanotic attacks, stridor, dyspnoea or no pulmonary complaints at all. Autopsy material commonly showed pneumonia in the opposite lung. Some cases showed maldevelopment of the whole chest wall, whilst others remained symmetrical on the two sides.

Embryology. According to Kiebel and Mall (1912) the lung bud appears early in foetal life $(2.5 \mathrm{~mm}$. embryo) as a rounded prominence below the laryngo-tracheal groove. Soon this divides into two pulmonary sacs ( $5 \mathrm{~mm}$. embryo) so that in agenesis (complete absence) of one lung the disturbance must arise before this stage is reached. The pulmonary vessels develop after this $(7 \mathrm{~mm}$. embryo), at the same time as the pulmonary sacs are differentiating into three buds on the right and two on the left; any vascular anomaly is therefor unlikely to cause complete absence of a lung. The lung buds grow into loose mesodermal tissue, repeatedly branching to form the bronchial tree, but formation of alveoli does not begin until the sixth month of foetal life and is not complete until the last few weeks of pregnancy.

Aetiology. Killingsworth and Hibbs (1939) reviewed the literature on this subject, mentioning pressure effects from amnion or thymus or some primary vascular disturbance as a cause for the maldevelopment, but conclude that Schwalbe's (1912) explanation of a developmental error of endogenous origin affecting the pulmonary, vascular and respiratory systems, is the most likely. The latter theory gains support from the case reported by Finkelstein (1924) of a pair of uniovular female twins who lived for one week. At autopsy, one had a rudimentary left lung and the other a rudimentary right lung.

The hypertrophy of the opposite lung is probably compensatory.

\section{Case Reports}

The following series of fourteen cases fall into three groups.

I. Cases 1 to 5. Absence or permanent underdevelopment of one lung, i.e. agenesis, aplasia, or permanent hypoplasia. 
II. Cases 6 to 11. Infants in the first year of life, showing displacement of heart and mediastinum with slow readjustment to normal within two or three years, probably a temporary hypoplasia.

III. Cases 12, 13 and 14. Children with a localized opacity in the $x$-ray. It is suggested that this may be caused by hypoplasia or atelectasis of part of a lung with no bronchial communication.

\section{Group I}

ABSENCE OR PERMANENT UNDERDEVELOPMENT OF ONE LUNG, i.e. AGNESIS, APLASIA OR PERMANENT HYPOPLASIA

Case 1. Aplasia OF THE Left lung. Sylvia S., aged one year, weight $17 \mathrm{lb} .12 \frac{1}{2} \mathrm{Oz}$., had spent the first five months of her life in a hospital because she had vomited periodically from birth; she had had no cough. An x-ray revealed ' congenital small or absent left lung.' She was the first child, normal delivery, doubtfully full term with a birth weight of $5 \mathrm{lb}$. Talipes equino-varus was noticed at birth. The parents were healthy, but the mother had a bad fall when two months pregnant. A second child born two years later was normal.

Clinical eXamination showed a microcephalic child not yet able to sit up; the circumference of head was 16.5 in., and the fontanelle was closed. There was congenital ptosis of both eyelids. The talipes was improving, according to the mother. The trachea felt central and the shape of the chest would have passed as normal, but was resonant to percussion both sides in front and dull on the left side behind where faint tubular breathing and distance heart sounds were heard; no apex beat was felt.

X-RAY OF THE CHEST (fig. 1) revealed a spina bifida

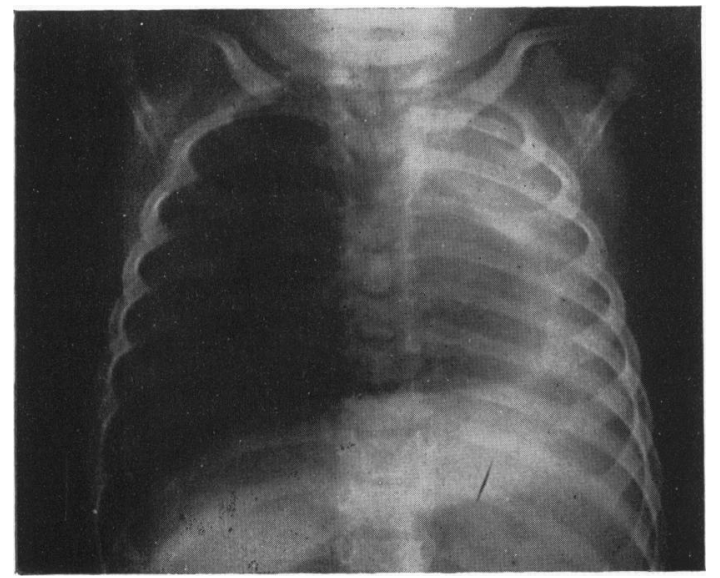

FIG. 1.-Case 1. Aplasia of the left lung with herniation of the right lung into the left chest.

in the first and second thoracic vertebrae, slight deviation of the trachea to the left and displacement of the heart to the left and backward. There appeared to be no left lung, but the right lung herniated through the anterior mediastinum to the left side.

BRONCHOSCOPY. The trachea was very narrow, and there was no sign of any main bronchus passing

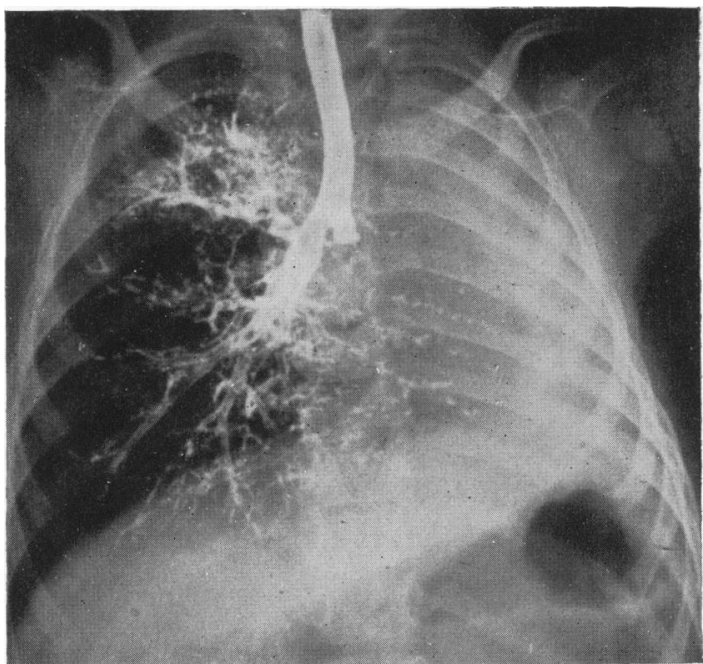

FIG. 2.-Case 1. Bronchogram, A-P view. Left main bronchus present as a stump. Right bronchial tree large, extending into the left chest.

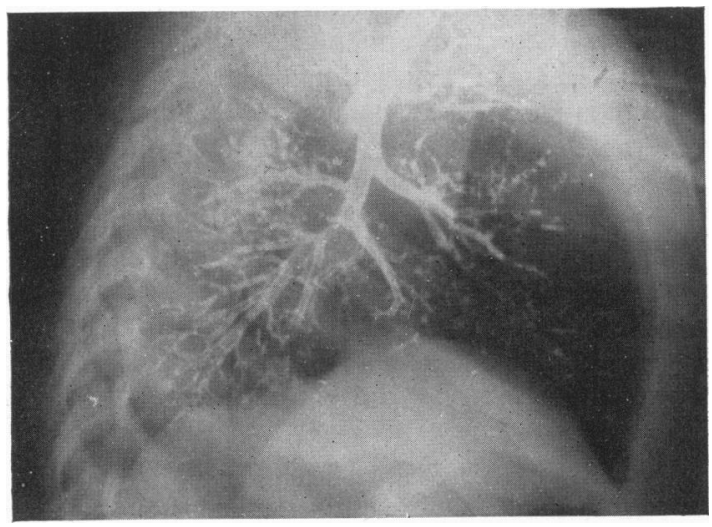

Fig. 3.-Case 1. Right lateral bronchogram. Anomalous right bronchial tree. (See case report.)

to the left lower lobe. The right main bronchus was very narrow and its main branches could not be seen. (This and subsequent bronchoscopies were kindly performed by Mr. J. Crooks.)

BRONCHOGRAM (fig. 2 and 3). The left main bronchus was present as a stump and the anomalous right bronchial tree was interpreted as showing a large pectoral branch of the upper lobe arising separately from the main bronchus and taking over part of the function of the right middle lobe which was diminutive in size.

Case 2. APlasia OR hYPOPlasia OF THE LeFT LUNG. Margaret F., aged ten years, weight $50 \frac{1}{2} \mathrm{lb}$., suffered from asthmatic bronchitis dating from a severe attack of pneumonia at three-and-a-half months old when she was nursed in a steam tent for four months. Since then she has had pneumonia twice, whooping cough very badly, measles with bronchitis, and 'pleurisy' twice. She was the third child; the first was still-born and the second died at thirteen days from pemphigus. The father's blood Wassermann reaction had been positive, but became negative one year before the birth of the patient. The mother's Wasšermann reaction was 
negative, but she had had one miscarriage. Margaret was a full-term child, normal delivery, birth weight $6 \mathrm{lb}$. $5 \mathrm{oz}$. After birth she had excessive mucus in the respiratory tract and gasped for breath. The mother stated that she had had no illness, accident, or haemorrhage during pregnancy, but on careful questioning she casually remarked that she had had herpes zoster in the first month.

Clinical eXamination. The patient appeared about the size of a child of seven years. The left side of the chest was flatter and smaller than the right, and the apex beat was high in the third intercostal space outside the nipple line. There was no clubbing, and the trachea felt central.

X-RAY OF THE CHEST (fig. 4). The heart was displaced to the left and backward, and the right lung

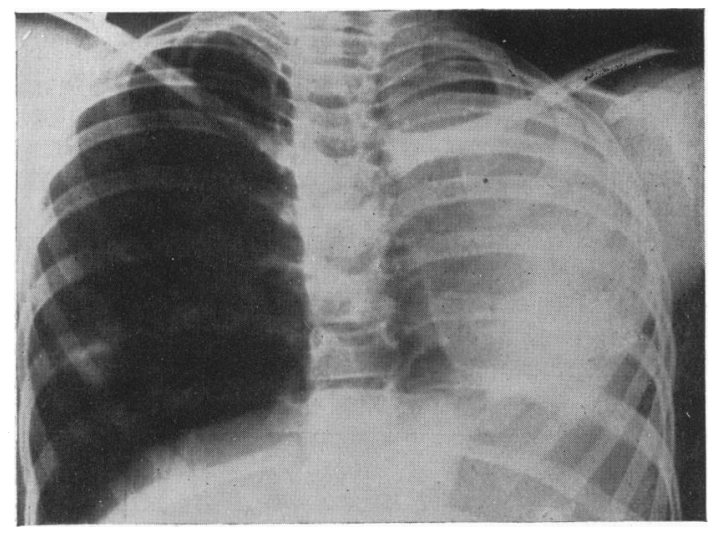

FIG. 4.-Case 2. Aplasia of left lung with herniation of right lung into the left chest.

had herniated through the anterior mediastinum to the left side. There was a calcified lesion in the right lung.

BRONCHOSCOPY. No main bronchus was seen on the left, the first main division was anteroposterior, and each branch then divided again almost immediately into two branches.

Bronchogram (fig. 5, 6, 7 and 8) revealed a large right bronchial tree with three large branches for the upper lobe probably arising separately from the main trunk, and smaller middle and lower lobe bronchi. The left main bronchus had rotated backward, lying in front of the vertebrae as a single small bronchus dividing in its lower third.

Case 3. Hypoplasia OF THE RIGHT LUNG. April K., aged five-and-a-half months, weight $8 \mathrm{lb}$., was

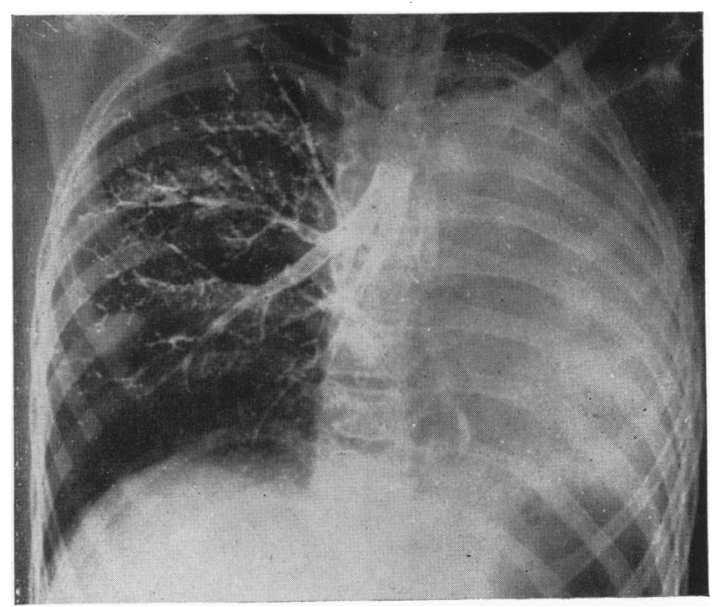

FIG. 5.-Case 2. Bronchogram, A-P view. Left main bronchus is probably the branch overlying the vertebrae. Right bronchial tree enlarged with abnormal branching. (See case report.)

admitted to hospital with the history that she had had bad coughing attacks since birth and was not gaining weight. She was born at full term (face presentation), weighing $5 \mathrm{lb}$. $4 \mathrm{oz}$. Oxygen had been required at birth and she had been blue for the first three days. She was breast fed for one month, but gain in weight had always been slow. The parents and two brothers were healthy and there had been no miscarriages, but the mother had nursed her two other boys through pneumonia, chickenpox and measles during the pregnancy.

Clinical EXAMINATION. The child was poorly developed and cyanosed with rapid breathing. Temperature $102 \cdot 8^{\circ} \mathrm{F}$., pulse 170 , respirations 76 per minute. Examination of the chest revealed no

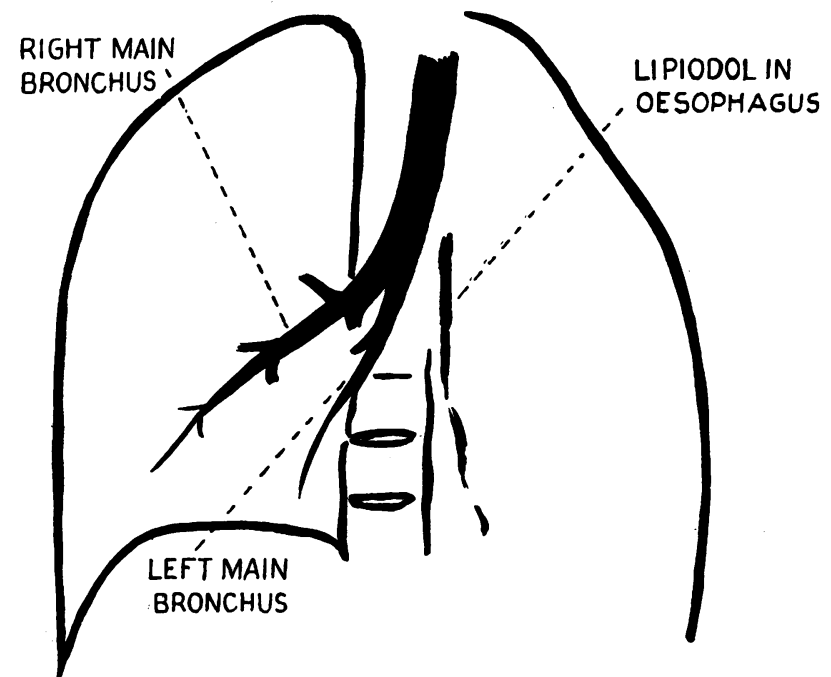

FIG. 6.-Case 2. Diagram of fig. 5. 
asymmetry, but the trachea was deviated to the right. There was a hyperresonant note on the left side and dull percussion note on the right, with the maximum apex beat just below the right nipple where a harsh systolic murmur could be heard.

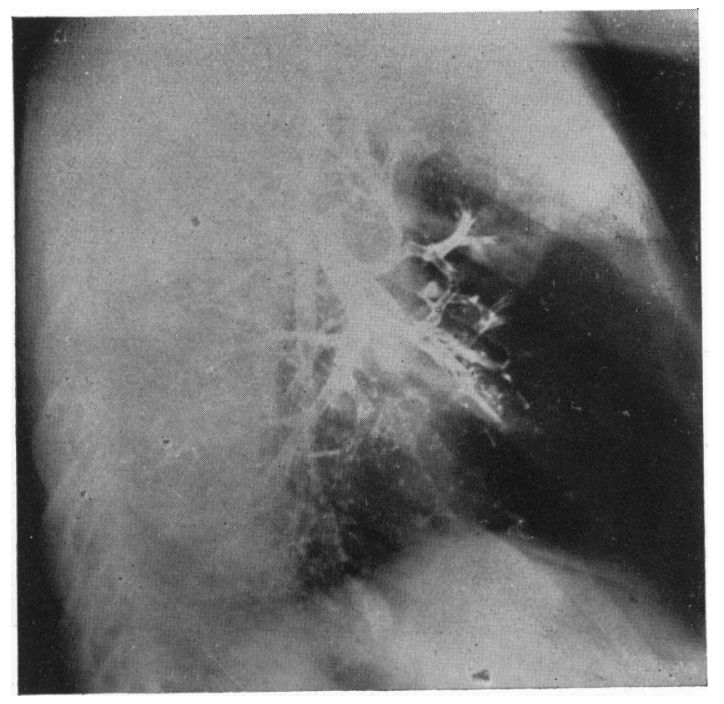

FIG. 7.-Case 2. Right lateral bronchogram. Left main bronchus lies immediately anterior to vertebral bodies and posterior to right main bronchus.

Numerous râles could be heard on the left side, but nothing on the right.

X-RAY OF THE CHEST showed the rib spaces equal on both sides, but the heart was displaced into the right side. The right diaphragm was high and the trachea was deviated to the right. An opacity at the left apex on admission cleared in later films.

BRONCHOGRAM (fig. 9) was performed when the temperature and physical signs had subsided. Only the trachea and main bronchi were filled, but they showed marked curving of the trachea to the right, with slight narrowing before its bifurcation into a large left main bronchus and diminutive right main bronchus sharply bending to the right.

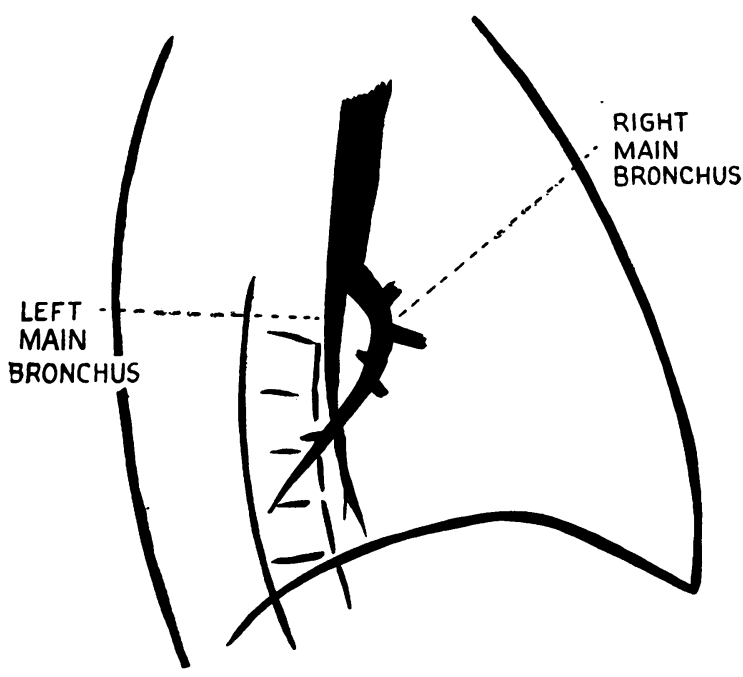

Fig. 8.-Case 2. Diagram of fig. 7.
Bronchoscopy. Mr. Crooks recorded that " the curved trachea straightened out on the bronchoscope so that a bifurcation could be seen. To the right and below was a minute tube leading presumably to the right lung. It expanded and contracted on respiration as would a normal bronchus. It was impossible to say if air came in and out. To the left and above, a larger tube led to the left lung and it was about normal in size and air passed easily through it.'

PROGRESS. After an initial course of sulphamezathine the child's condition improved, the temperature fell to normal and the respirations to 45 per minute. The child was discharged home after a month, still with a few moist sounds in the chest. Two months later she was readmitted as an emergency, having had a cough for one week. She was cyanosed, breathless, wheezing and coughing, and there was swelling of the hands and feet. In spite of oxygen and sulphonamide therapy, she died the following day.

Post-mortem report (fig. 10 and 11) by Dr. M. Bodian. A. K., aged eight months. A wasted, cyanosed infant.

ThORAX. Trachea showed deviation to the right.

HEART. A large, quadrangular heart filled the whole of the right thoracic cavity. Both ventricles were hypertrophic; the valves were normal. An interventricular septum defect of about $\frac{1}{4}$ inch

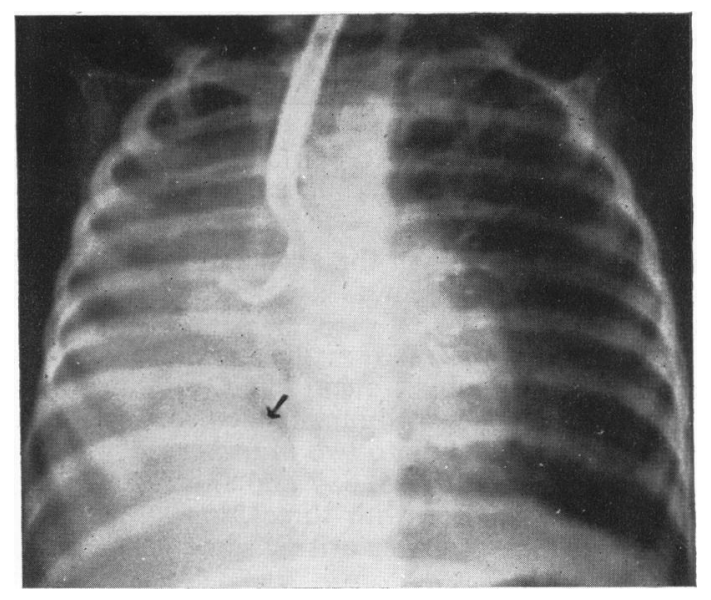

FIG. 9.-Case 3. Bronchogram. Incomplete filling of bronchial tree, showing curving of trachea to the right with large left main bronchus and diminutive right main bronchus. Hypoplasia of right lung. Heart displaced into right chest. Right diaphragm (marked with arrow) is high.

diameter was present at the site of the membranous septum.

LUNGS. Behind the heart and fully covered by it lay a very small hypoplastic right lung which showed no division into lobes. The right main bronchus was much narrower than the left one. The three secondary bronchi were patent throughout, leading to what would normally have been upper, mid- and lower lobes. The lower lobe of the left lung showed marked consolidation and pleurisy.

MENINGES, LIVER, SPLEEN and KIDNEYS were congested. All the other organs appeared to be normal.

Histology of the hypoplastic lung showed no 


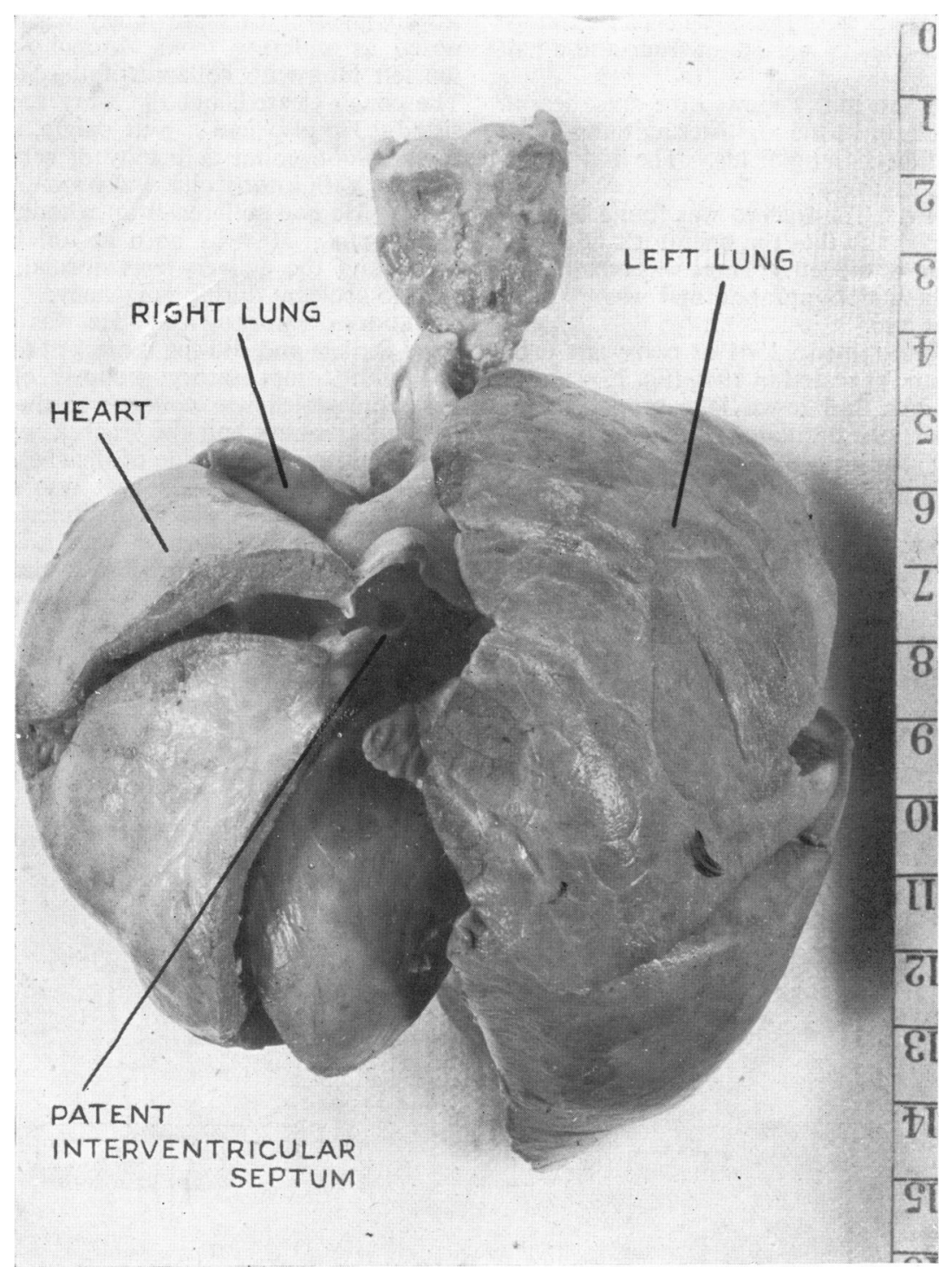

Fig. 10.-Case 3. P.M. specimen, anterior view. Hypoplasia right lung and patent interventricular septum. Right lung behind the heart and hardly visible. left lung enlarged.

proper alveolar formation in most parts. Where laid down, alveoli were primitive and lined by cuboidal epithelium. The bronchioles were of normal appearance.

Case 4. Hypoplasia Right lung. Alfreda W., aged two years seven months, weighing $20 \frac{3}{4} \mathrm{lb}$., attended hospital for recurrent coughs and colds, which had been worse since pneumonia three months previously. Her birth weight was $4 \mathrm{lb}$. $12 \mathrm{oz}$., but she was reported to be full term. Delivery was normal, but her mother had a slight fall when two months pregnant. The infant had been slow in gaining weight since birth. A grandmother had asthma and grandfather died of bronchiectasis. There are three other children, one of which is wheezy.

Clinical examination. The patient was noticed to be small for her age with a frail appearance. There was some flattening of the right side of her chest and trachea was displaced to the right, but movement was equal on the two sides. The apex beat was felt just to the right of the sternum and percussion note was dull on the right side anteriorly, and also to a less marked degree on the right behind. Faint tubular breath sounds were heard over the right lung, but no adventitious sounds. Later, during an upper respiratory tract infection, however, a unilateral wheeze with rhonchi was heard on the right side. There was no clubbing. The abdominal viscera were not transposed.

X-RAY OF CHEST (fig. 12) revealed the heart situated in the right chest, and the trachea deviated to the right; translucency of the right lung was equal to that of the left. In the lateral x-ray there was a translucent area in front of the heart 
displacing it backwards. There has been no change in this picture over a period of four-and-a-half years.

SCREENING OF THE CHEST showed the apex beat in the mid-line just above the xiphisternum and equal translucency of both lung fields. The right lung was displaced posteriorly.

BRONCHOSCOPY. The trachea was found to bend sharply to the right so that the operator's head had to bend well over to the left. There was no stricture of the trachea and nothing abnormal was detected in the bronchial tree.

RIGHT BRONCHOGRAM in 1941 at two years eight months of age and repeated in 1945 (fig. 13) showed small right middle and lower lobe bronchi and a large right upper lobe bronchus with a rudimentary branch arising separately from the right main bronchus.

Case 5. Hypoplasia left lung. Ronald B., aged six years, weight $39 \frac{1}{2} \mathrm{lb}$., first attended hospital for cough five years previously when he was diagnosed as suffering from 'broncho-pneumonia of the left lung with collapse of the left upper lobe.' The cough cleared, but the $\mathrm{x}$-ray appearances persisted. He also had a cleft palate, stenosis of the trachea, congenital deformity of cervical vertebrae (fig. 14) with a torticollis and probably a congenital heart. He had suffered from whooping cough and chickenpox. He was born at full term, weighing $9 \mathrm{lb}$., and the delivery was normal. The mother had no accident during pregnancy.

Clinical examination. He was a little undersized for age and showed a marked torticollis to the left with compensatory scoliosis of the thoracic vertebrae which was concave to the right. There was no clubbing and the trachea was central, but movement of the left side of the chest was less than on the right. The apex beat was situated in the fourth intercostal space in the anterior axillary line where a systolic murmur was heard. The percussion note was impaired over the whole of the

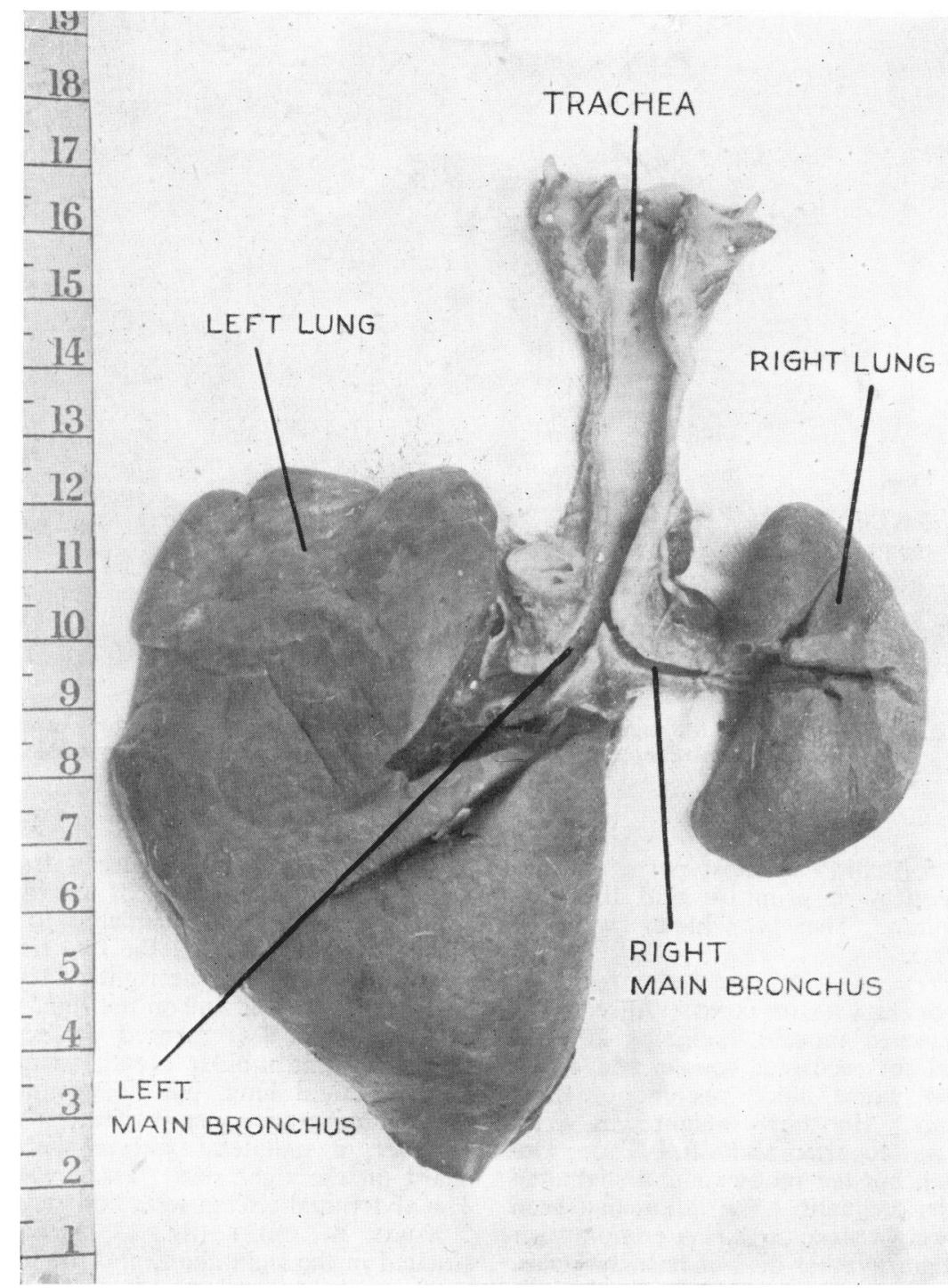

Fig. 11.-Case 3. P.M. specimen, posterior view. Hypoplastic right lung with small bronchus shown in contrast to large left lung and bronchus. 


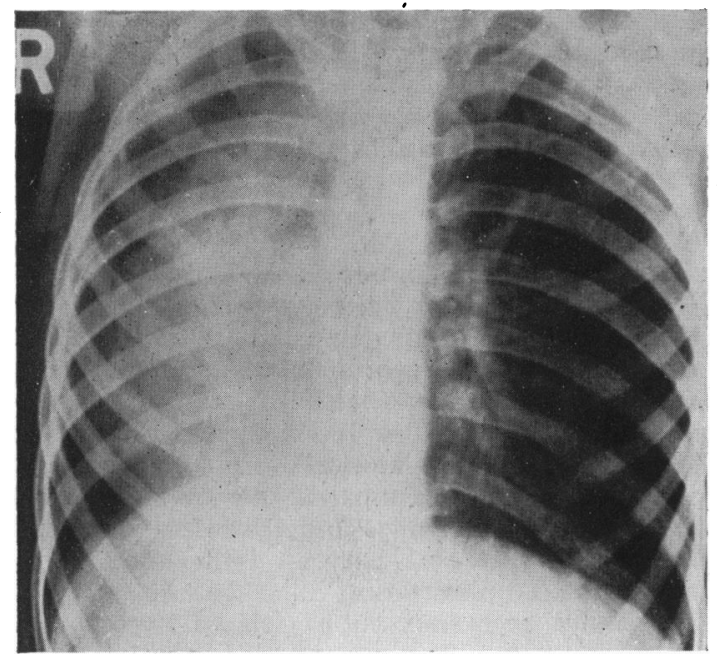

FIG. 12.-Case 4. Hypoplasia of right lung. Heart is situated in the right chest, but translucency of right and left lungs is equal.

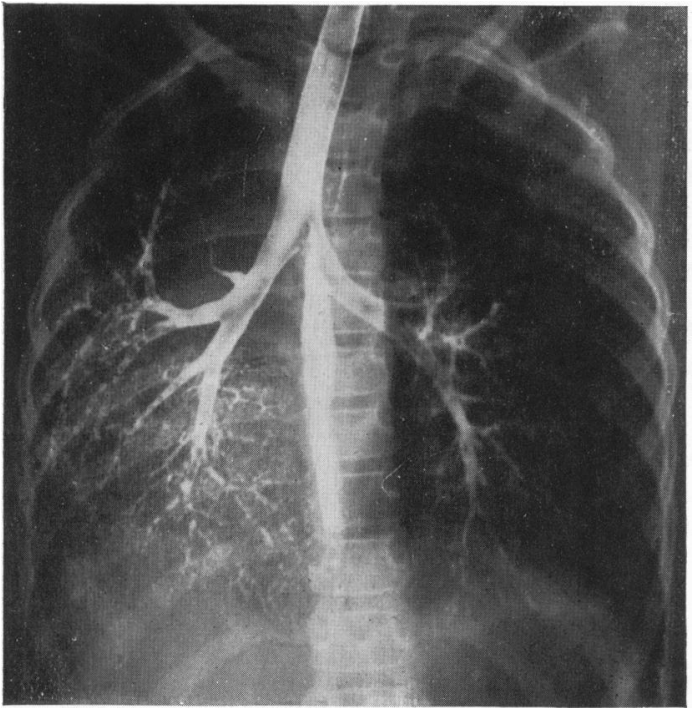

Fig. 13.-Case 4. Right bronchogram, A-P view. Anatomical anomaly of right bronchial tree. (See case report.)

left chest, but air entry was good. Scattered rhonchi, which later cleared, were heard on admission.

X-RAY OF CHEST (fig. 14) showed crowding of the ribs on the left side with displacement of heart to the left and loss of translucency in the left chest. The trachea was slightly displaced to the right. In the lateral view, an area of hypertranslucency extended anteriorly in the superior mediastinum and in front of the heart, which was displaced backwards. There has been no change in this picture for the last four-and-a-half years. The abnormality of the cervical vertebrae and resultant scoliosis make interpretation of this $\mathrm{x}$-ray difficult without further corroboratory evidence.

SCREENING OF THE CHEST. Dr. L. G. Blair reported 'Heart is to the left. Right lung extends across the mid-line. Left lung is emphysematous and the bronchogram agrees with the diagnosis of partial agenesis of the lung.'

BRONCHOSCOPY. There was a definite narrowing towards the lower end of the trachea that was more difficult to pass than the glottis. On withdrawing the bronchoscope, the constriction was seen to be a localized narrowing of normal contour. The trachea appeared to be deviated to the left as the bronchoscope had to be tilted considerably to the right, so stretching the mouth. The right bronchial tree was normal, the left bronchial tree was difficult to approach, but the bronchi appeared smaller than normal.

LEFT BRONCHOGRAM (fig. 15) revealed a small left lung displaced backwards with a long main bronchus. The abnormality of the bronchial tree was difficult to decipher; the upper lobe was small and there appeared to be no lingular bronchus. Permission for a repeat bronchogram has been refused by the parents.

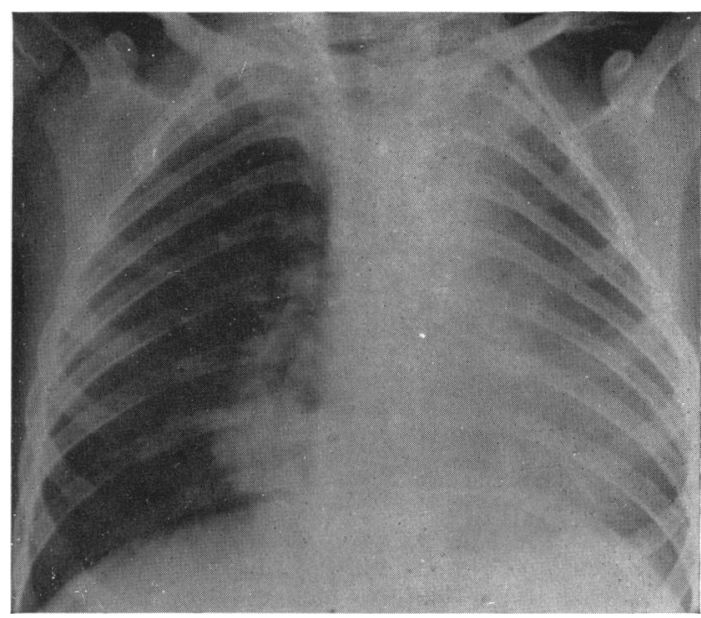

FIG. 14.-Case 5. Hypoplasia of left lung. Heart is displaced to the left. Congenital abnormality of cervical vertebrae produces scoliosis.

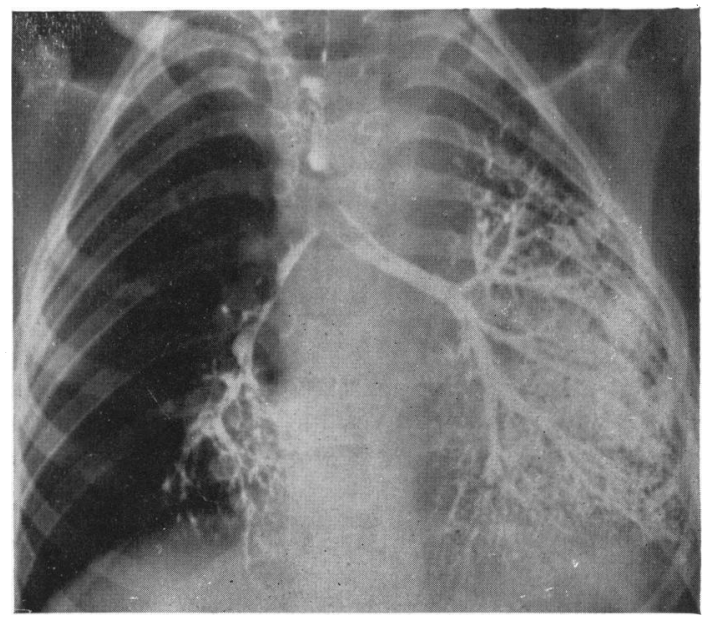

Fig. 15.-Case 5. Left bronchogram, A-P view. Anatomical anomaly of left bronchial tree. (See case report.) 


\section{Group II}

INFANTS IN THE FIRST YEAR OF LIFE SHOWING DISPLACEMENT OF HEART AND MEDIASTINUM WITH SLOW RE-ADJUSTMENT TO NORMAL WITHIN TWO OR THREE YEARS, PROBABLY A TEMPORARY HYPOPLASIA

Case 6. Phyllis W., aged five-and-a-half months, weighing $15 \mathrm{lb} .11 \mathrm{oz}$., attended hospital for cough at night and occasional vomiting. The mother stated that she contracted whooping cough at three weeks old and measles at four months. She was the third baby (the other children being healthy), was born at full term weighing $8 \frac{1}{2} \mathrm{lb}$., and delivery was normal. The mother had no illness, accident or haemorrhage during the pregnancy.

Clinical EXamination. She was a healthy, happy, well-nourished child. There was asymmetry of the skull (plagiocephaly) but no scoliosis. The

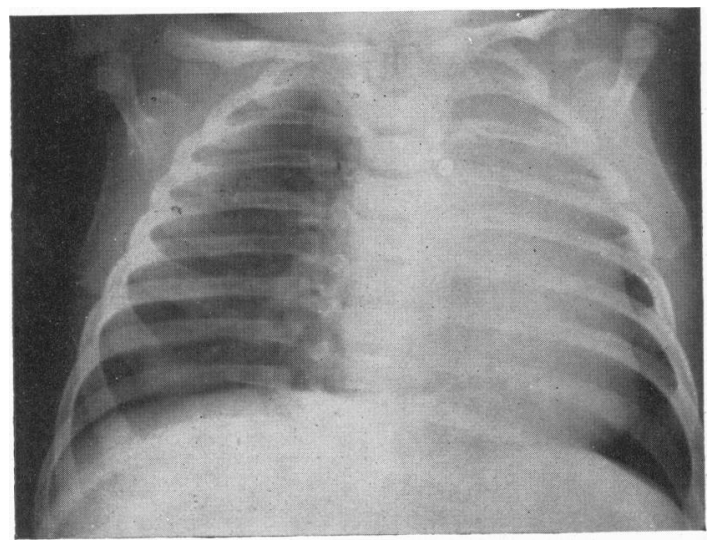

FIG. 16.-Case 6 at five months. Temporary hypoplasia of left lung. Heart is displaced to the left, trachea to the right, but there is hypertranslucency of the left lung.

left chest did not move quite so well as the right. The apex beat was felt in the axilla and there was impaired percussion note at the left apex. Air entry was good on the left side and there were no adventitious sounds.

X-RAY OF CHEST at five months (fig. 16) showed the heart displaced to the left and the trachea to the right, with hypertranslucency of the left lung. Six months later there was still considerable displacement of the heart to the left and a lateral x-ray at this time showed the heart displaced backwards. At the age of two years ten months the heart was more central and in the last x-ray taken at four vears two months the heart is practically in its normal position.

SCREENING OF THE CHEST at five-and-a-half months showed a shift of the heart and mediastinum to the left, but no evidence of collapse in the left lung. If pertussis had been the cause of the mediastinal shift, collapse of the left lung, or obstructive emphysema of the right, would have been expected.

BRONCHOSCOPY and BRONCHOGRAM were not performed.

Progress. Apart from a periodic cough associated with naso-pharyngeal infections, the child has kept well.

Case 7. John K., aged five-and-a-half months, weighing $14 \mathrm{lb} .13 \mathrm{oz}$., attended hospital for shivering and cold for three days, and loss of appetite for one day. There had been no previous illness. He was the second child, born at full term weighing $6 \mathrm{lb}$. $13 \mathrm{oz}$., and delivery had been normal. The mother had no illness, accident or haemorrhage during the pregnancy.

Clinical examination. He also showed an asymmetry of the skull, but no scoliosis. The right side of the chest was flattened particularly in the axilla and the sternum depressed so that the ribs formed a prominent vertical ridge in the nipple line. Clinically, the child presented the picture of pneumonia with temperature $100.4^{\circ} \mathrm{F}$. and respiration 63 per minute; the alae nasi were working. The percussion note was impaired all over the right chest with scattered râles and friction at the right base. Rhonchi were heard in both lungs. Following the administration of sulphadiazine, the temperature and respirations fell to normal, the adventitious sounds disappeared from the lungs, but the percussion note remained impaired at the right apex with tubular breathing. Air entry was equal in the two lungs but the deformity of the chest persisted.

X-RAY OF CHEST at five-and-a-half months (fig. 17) showed flattening of the right chest and narrowing of the rib spaces. The heart and mediastinum were displaced to the right, particularly the upper mediastinum which appeared to occupy the right apex. The child was then x-rayed after being tilted to the left, so that the rib ends were equidistant from the centre. In this position it was noted that although the clavicles were not central, the heart was still displaced to the right and there was nothing to suggest collapse of the right upper lobe, the right lung being as translucent as the left. At one year old the displacement of the heart was less marked, and at two years nine months the

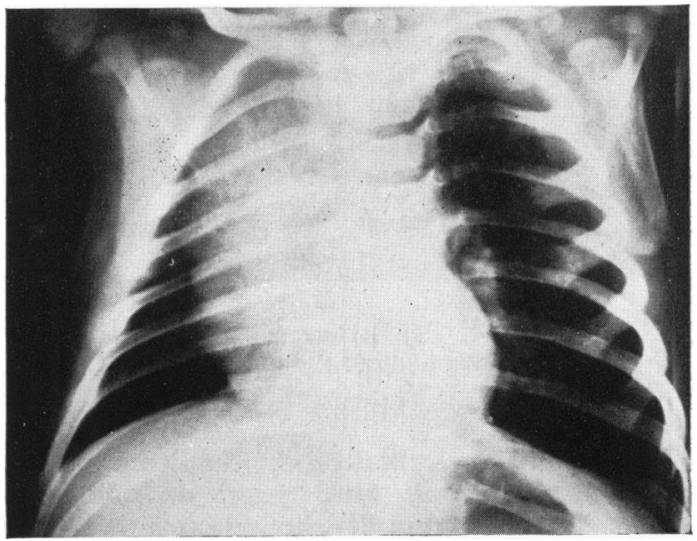

FIG. 17.-Case 7 at $5 \frac{1}{2}$ months. Temporary hypoplasia of right lung. There is flattening of the right chest with narrowing of rib spaces. Heart and mediastinum are displaced to the right and occupying the right apex.

heart and mediastinum had returned to their normal position. The early lateral $x$-rays were too poor for reproduction, but they did show an area of emphysema antero-superiorly, probably an extension of the left upper lobe into the anterior mediastinum.

SCREENING THE CHEST showed the heart and 
mediastinum, particularly the superior part, displaced to the right, but there appeared to be full aeration of the right lung, as the translucency was equal to that on the left. There was no evidence of collapse of the right upper lobe.

BRONCHOSCOPY. This was performed two weeks after the onset of pneumonia. The right upper lobe bronchus had a very small opening with thick congested mucosa but no excess secretion. Bubbles appeared at the mouth of the bronchus on respiration, indicating that air was passing. The rest of the bronchial tree was normal.

\section{BRONCHOGRAM was not performed.}

Progress. The child has remained quite well since the pneumonia at five-and-a-half months. He has no cough and I am informed that the flattening of the right side soon became imperceptible.

Case 8. Brian W., aged three-and-a-half months, weighing $13 \mathrm{lb} .4 \mathrm{oz}$., was noticed by the Infant Welfare doctor to hold his head backward and to the right side; this could be corrected without any difficulty or pain to the child and no congenital deformities were detected except in the chest. He was the first child; the delivery was normal, the birth weight $7 \mathrm{lb} .12 \mathrm{oz}$., there had been no previous illness and no cough. The head posture was easily corrected by the mother carrying the child on the opposite arm.

Clinical examination. Apart from the posture of the head, there was facial asymmetry and slight

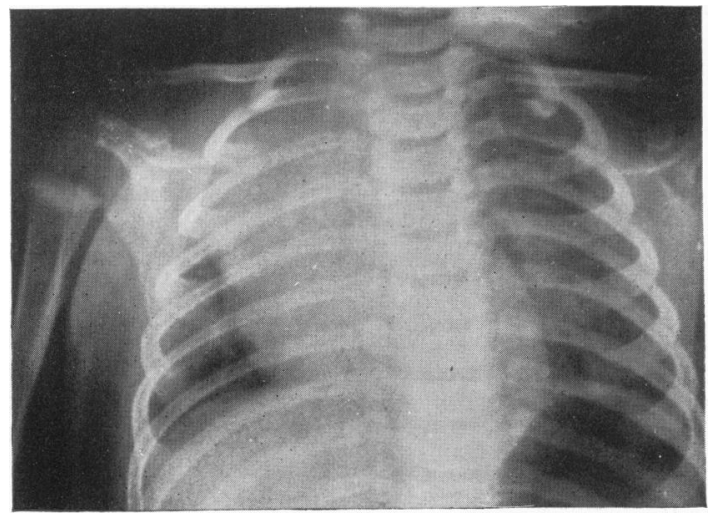

Fig. 18.-Case 8 at seven months. Temporary hypoplasia of right lung. Heart and mediastinum are displaced into the right chest. No flattening of right chest.

scoliosis of the upper thoracic vertebrae which was concave to the right, so that the right chest appeared smaller. The infant was difficult to examine and the borders of the heart were not delineated clinically, but no murmurs were heard. On percussion, the note was emphysematous and the air entry was equal on the two sides.

X-RAY OF CHEST at three-and-a-half months was not central, but at seven months of age (fig. 18) it showed displacement of the heart and mediastinum to the right, particularly in the upper part. The scoliosis was practically corrected and the clavicles were symmetrical, but the line of the costo-chondral junctions was asymmetrical. Serial $x$-rays over a period of two-and-a-half years showed a gradual return of the heart and mediastinum to the normal position, and fig. 19 reproduces the last $\mathrm{X}$-ray taken at the age of three years.

SCREENING OF THE CHEST demonstrated the displacement of heart and mediastinum to the right. There appeared to be also a separate rounded opacity at the right apex situated anteriorly which did not pulsate but increased in size on crying and diminished in size on inspiration. A superimposed large thymus was suspected. The translucency of right and left lung fields was equal. Further screening at three years of age revealed no abnormality.

BRONCHOSCOPY and BRONCHOGRAM were not performed.

PROGRESS. The child has always been very well. There is now no asymmetry of face or chest.

Case 9. John C., aged ten months, weighing $10 \mathrm{lb} .7 \mathrm{oz}$., was brought to hospital because he

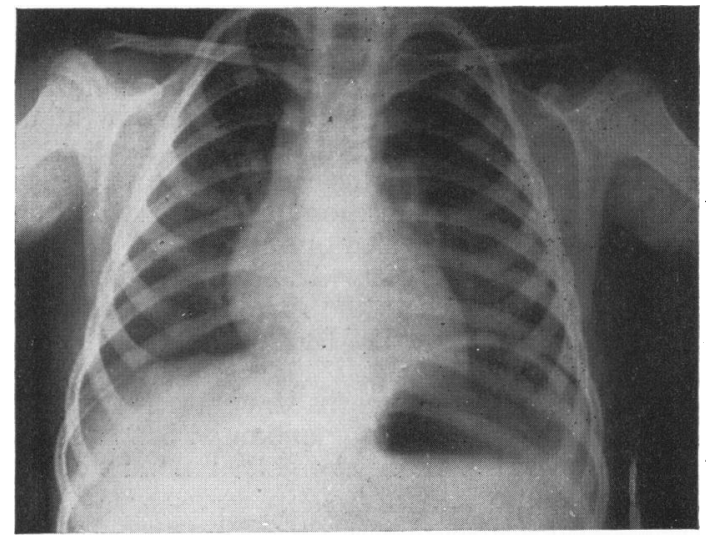

FIG. 19.-Case 8 at three years. Heart is practically in its normal position.

failed to thrive and vomited after most feeds. He was a twin, six weeks premature, the birth weight being $4 \mathrm{lb}$. His twin sister progressed satisfactorily. There were no previous illnesses. During the pregnancy his mother suffered from anaemia in the early months and had at the end of the fifth month what her doctor termed a precursor to a miscarriage.

Clinical examination. The infant was wasted and showed a marked asymmetry of the face with prominent veins on the scalp and chest. The fontanelle was large. There was no scoliosis and no flattening of the chest. The apex beat was difficult to define, but there was a diffuse pulsation under and to the right of the sternum. Air entry was equal in the two lungs and there were no adventitious sounds.

X-RAY OF CHEST (fig. 20) showed displacement of heart and mediastinum with the trachea to the right. The translucency of the lung fields was equal, but the line of the costo-chondral junctions was asymmetrical. Lareral $x$-rays showed an area of emphysema antero-superiorly. Serial $x$-rays over a period of two-and-a-half years showed a gradual return of the heart and mediastinum to the normal position. The last x-ray was taken at the age of three-and-a-half years, and confirmed the normal position at this time.

SCREENING THE CHEST. The heart and mediastinum were displaced to the right and the maximum 
impulse (apex beat) was on the left border of the heart. Both lungs aerated equally.

BARIUM SWALLOW revealed a congenitally short oesophagus with stricture.

BRONCHOSCOPY and BRONCHOGRAM were not performed.

Progress. After a very difficult period when he developed gastro-enteritis, the patient made a slow but steady improvement. He has now almost reached normal weight for age. He vomits only occasionally and the asymmetry of the face is less noticeable.

Case 10. Roy G., aged nine months, weighing $21 \mathrm{lb} .3 \mathrm{oz}$., was admitted to hospital for repair of harelip. Following the operation he developed a cough and was therefore x-rayed. He had clinical and $x$-ray evidence of rickets with bossing of the head, but there was no asymmetry of head or chest. He was the fifth child and there were no previous illnesses.

X-RAY OF THE CHEST at nine months of age (fig. 21) showed the heart, trachea and mediastinum displaced to the right with a rounded shadow at the right hilum, probably the thymus. The last $x$-ray taken at eighteen months of age showed slight improvement in the position of the heart and disappearance of the rounded opacity.

SCREENING THE CHEST. The heart and mediastinum were displaced to the right, and aeration of the two lungs was equal. The rounded opacity was difficult to define.

Progress. At ten months he contracted whooping cough and developed pneumonia, but had fully recovered when last seen at eighteen months of age, when he had no cough.

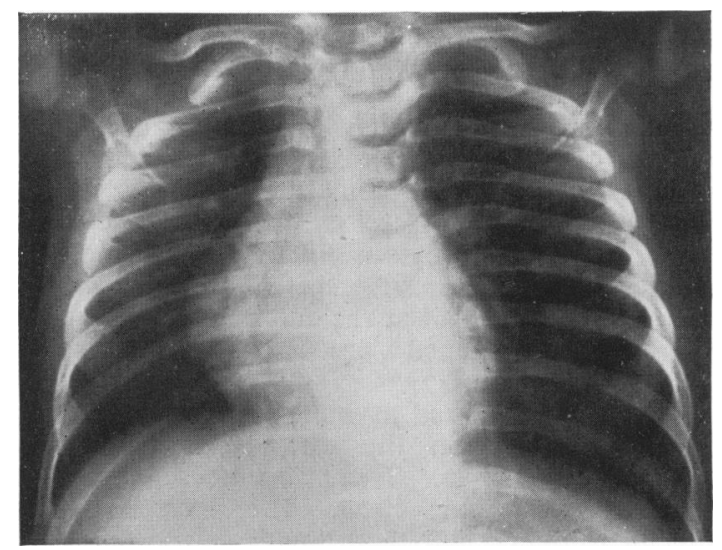

FIG. 20.-Case 9 at ten months. Temporary hypoplasia of right lung. Heart and mediastinum with trachea are displaced to the right.

Case 11. Christopher K., aged ten weeks, was admitted to hospital in a dyspnoeic state with attacks of cyanosis which he had had since birth. $\mathrm{He}$ was the fourth child, and was one of twins; the other twin was a miscarriage at the third month of pregnancy. Christopher was a full term child; the delivery was normal, and the birth weight $7 \mathrm{lb}$. $12 \mathrm{oz}$. The mother had no illness or accident apart from the miscarriage during the pregnancy. There was no cough.

Clinical eXAmination. He was a sickly infant,

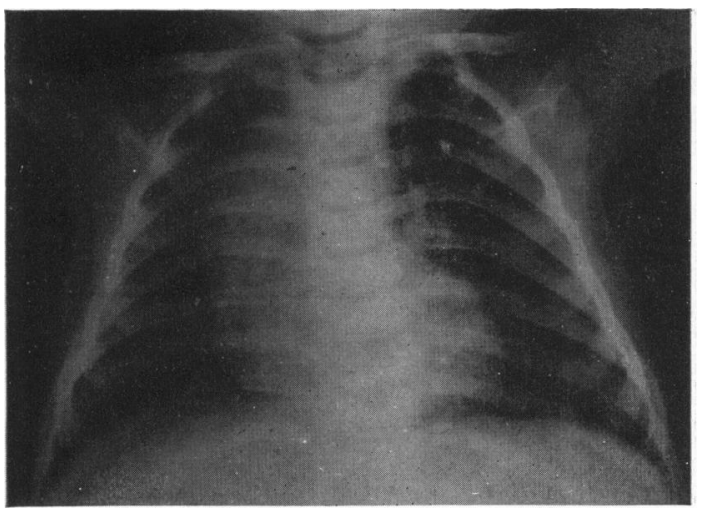

FIG. 21.-Case 10 at nine months. Temporary hypoplasia of right lung. Heart, mediastinum and trachea are displaced to the right. Rounded opacity at right hilum is probably thymus.

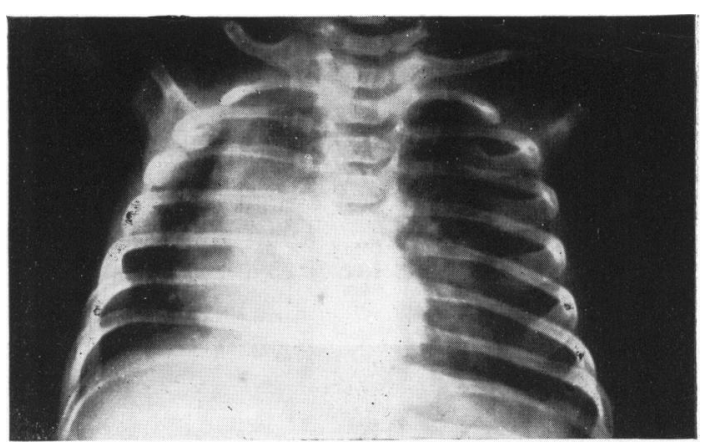

Fig. 22.-Case 11 at $2 \frac{1}{2}$ months. Temporary hypoplasia of right lung. Child is slightly rotated to the right. Heart and mediastinum are displaced to the right with herniation of left lung into the right chest. Trachea is central.

cyanosed, dyspnoeic and sweating. He had a cleft palate with a severe degree of micrognathia causing respiratory stridor. There was no asymmetry of the head or chest, but the latter showed inspiratory recession of the intercostal spaces and ribs with pigeon deformity.

X-RAY OF CHEST (fig. 22). At the age of two-anda-half months, $x$-rays were taken in three positions, viz. a little to the right, central and a little to the left, and in all it was observed that the heart and mediastinum were displaced to the right; the trachea, however, was central. A lateral x-ray showed a strip of emphysema anteriorly with displacement of the heart backward.

SCREENING THE CHEST. Dr. L. G. Blair reported: 'The heart is definitely and permanently displaced to the right, ? due to collapse of a portion of the lung, although I cannot see any lung so collapsed, ? partial agenesis. There is some consolidation in the right mid-zone.'

Progress. At first the infant's condition improved, but he was readmitted suffering with gastroenteritis, and although he recovered from this, he finally died at the age of four months from measles and broncho-pneumonia. Unfortunately he was admitted to, and died in, a fever hospital without details of his former history being available; no post mortem was performed. 


\section{Group III}

INFANTS WITH A LOCALIZED TRIANGULAR OPACITY IN THE X-RAY

(It is suggested that this might be caused by hypoplasia or atelectasis of part of a lung with no bronchial communication.)

Case 12. Garry W., aged two years and four months, weighing $29 \mathrm{lb}$., was admitted to hospital for second-stage cleft palate operation and was $\mathrm{x}$-rayed because he had a cough; this had persisted since whooping cough twenty-one months previously. He was born at full term, weighing $8 \mathrm{lb}$., and delivery was normal. When two to three months pregnant his mother had a bad fall downstairs. There was one other child in the family, who was healthy.

Clinical eXamination. The child looked well and there were no abnormal physical signs in the chest. The Mantoux tuberculin test 1 in 1,000 was negative.

X-RAY OF THE CHEST at two years and four months (fig. 23 and 24) showed a triangular shadow in the upper mediastinum on the right side with a concave outer margin. In the oblique and lateral positions

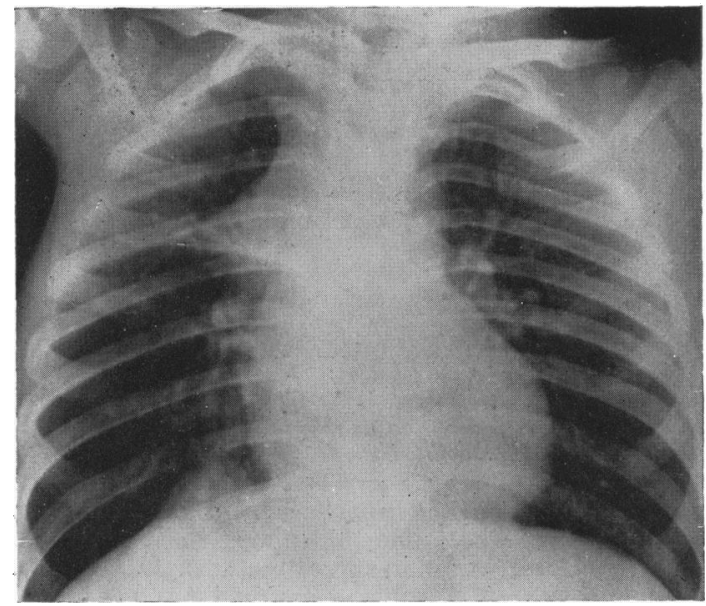

Fig. 23.-Case 12 (A-P view). ?Hypoplasia of part of right upper lobe. A triangular opacity in the right upper mediastinum is seen with a small hernia of the right diaphragm.
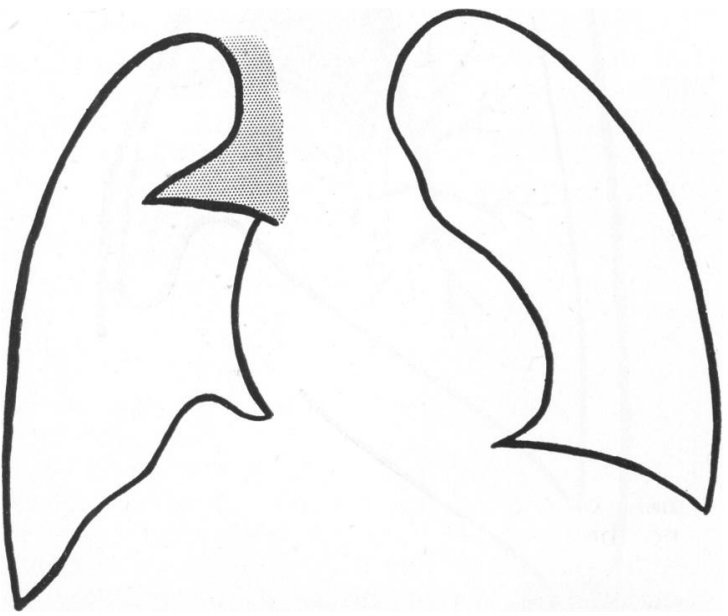

Fig. 24.-Case 12. Diagram of fig. 23.

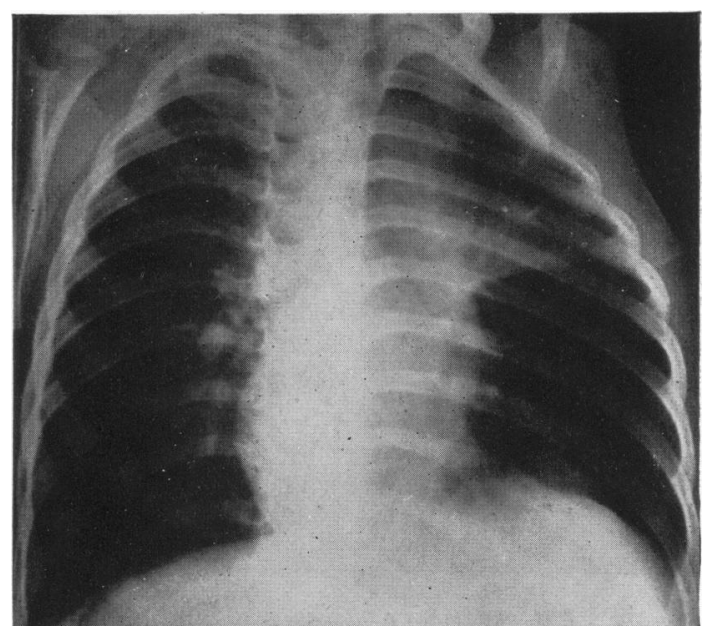

FIG. 25.-Case 12 (right oblique position). The triangular opacity is visible in the right upper lobe area.

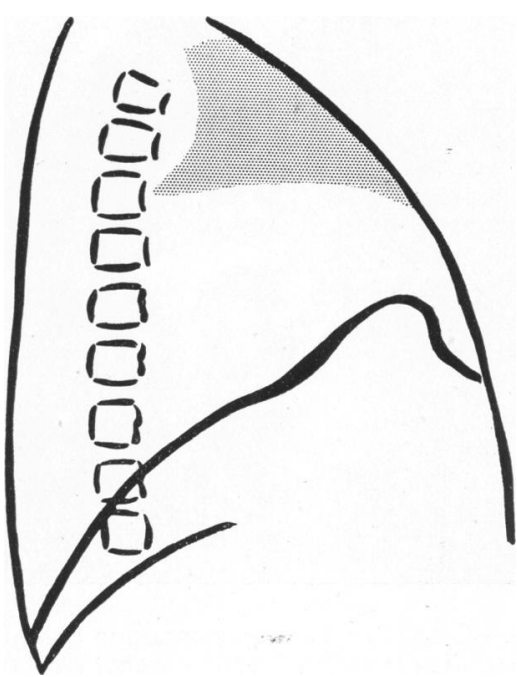

Fig. 26.-Case 12. Diagram of right lateral position. The triangular opacity is occupying the usual position of the pectoral segment.

(fig. 25 and 26) this opacity takes the shape of a collapse of the pectoral part of the right upper lobe. There is also a small hernia of the right diaphragm. Serial x-rays taken over a period of two years show the shadow comparatively, but not actually, smaller.

SCREENING showed that the opacity was situated anteriorly and limited below by the lesser fissure. It diminished in size on inspiration and enlarged on expiration.

BRONCHOSCOPY. The right main bronchus was very small with loose puckered mucosa and the bronchoscope would not pass. The left bronchial tree appeared normal.

RIGHT BRONCHOGRAM (figs. 27, 28, 29, and 30) revealed two narrowings of the right main bronchus before its first division. There appeared to be no bronchus entering the triangular opacity. A repeat of the bronchogram at four years eight months still revealed no bronchus entering the opaque area. 


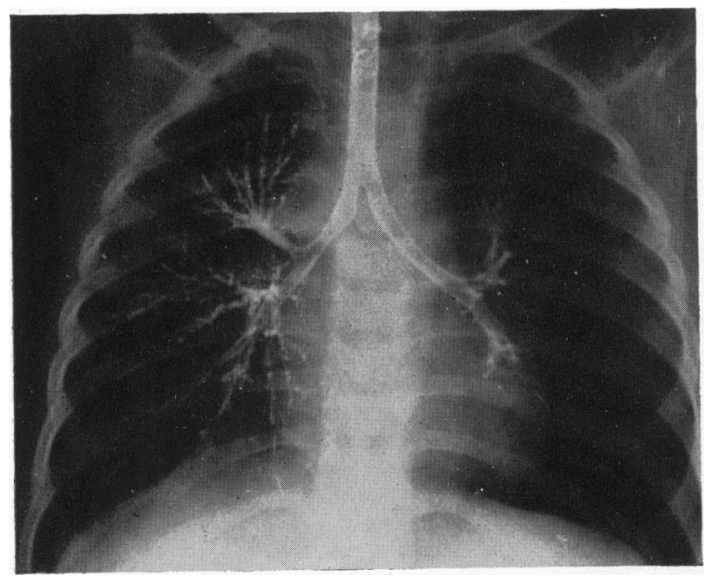

FIG. 27.-Case 12 (right bronchogram, A-P view). No bronchus enters the triangular opacity. There is a double stricture of the right main bronchus.

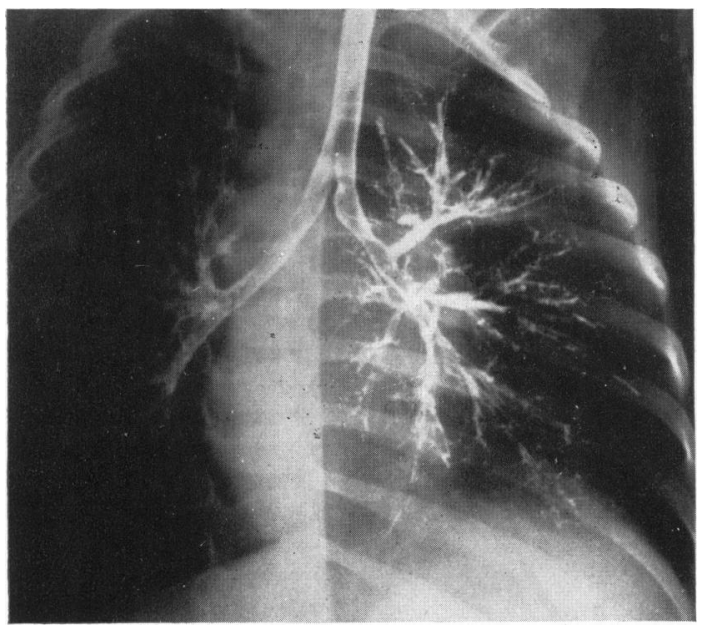

FIG. 28.-Case 12 (right bronchogram in oblique position). The double stricture of right main bronchus is clearly visible. Anatomical position of the bronchi not helpful in this position.

Progress. Apart from intermittent colds and coughs the child is making satisfactory progress and is overweight for age.

Case 13. Sidney C., aged five months, was first brought to hospital because he had been chesty since 2 months old. He was the third child, born full term, normal delivery, birth weight $7 \frac{1}{2} \mathrm{lb}$. There had been no previous illnesses. His mother had no illness, accident or haemorrhage during the pregnancy.

Clinical examination. The breathing was partially obstructed and breath sounds were harsh in character. There were no adventitious sounds. The tuberculin patch test was negative.

X-RAY OF THE CHEST at five months (fig. 31 and 32) showed a triangular shadow in the right upper mediastinum with convex borders. It was difficult to define the shadow in the lateral $x$-ray, but it appeared to be anterior in the oblique (fig. 33). The last $x$-ray taken at two years and two months showed little change.
SCreening the Chest. Dr. L. G. Blair reported: - The opacity, spreading out into the right lung, is situated anteriorly, and I think is probably due to collapse of portion of the upper lobe.' It was observed to diminish in size on inspiration and enlarge on expiration.

BRONCHOSCOPY. No abnormality was detected in the bronchial tree.

Progress. At one year and four months the child contracted whooping cough. At two years and two months the child had no cough but was backward in talking and was rolling his head; lowgrade mentality was suspected.

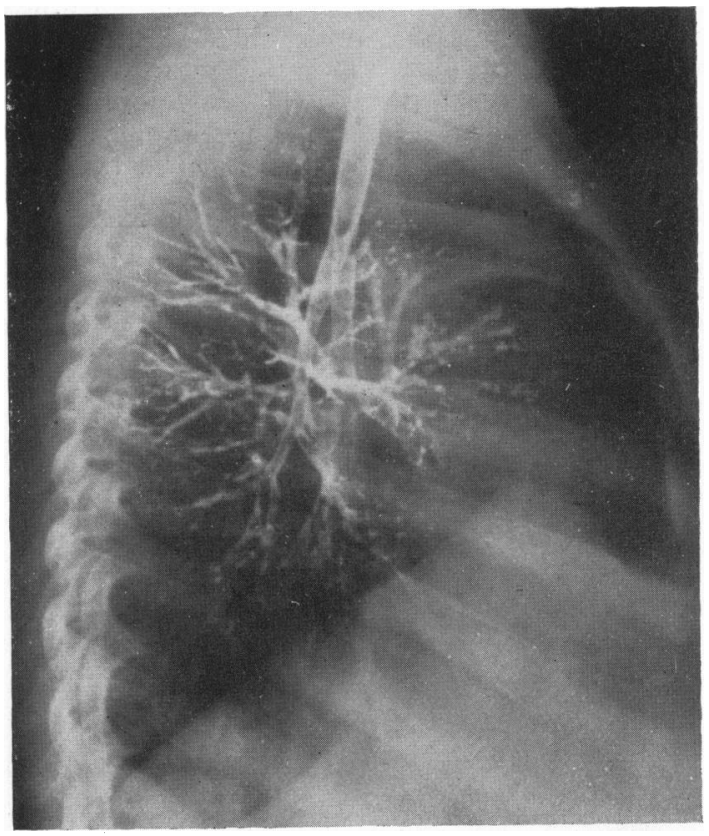

FIG. 29.-Case 12 (right bronchogram in lateral position. There is some filling in the opposite side). No bronchus appears to supply the triangular opacity.

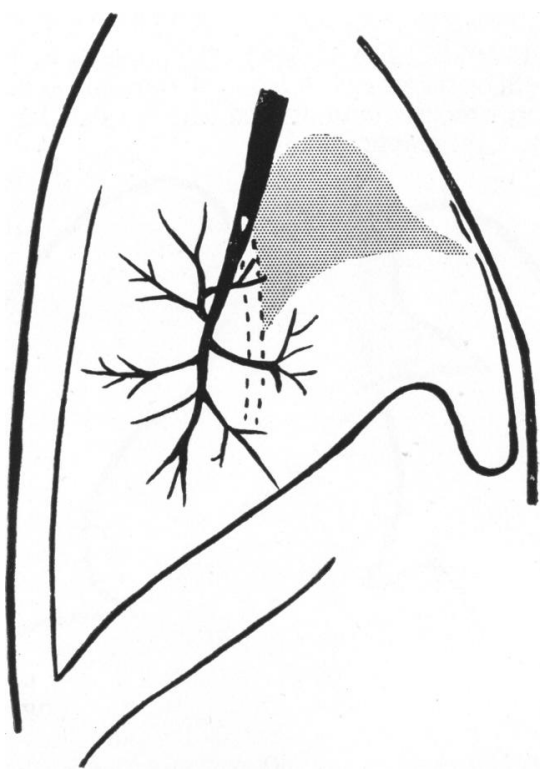

Fig. 30.-Case 12. Diagram of fig. 29. 


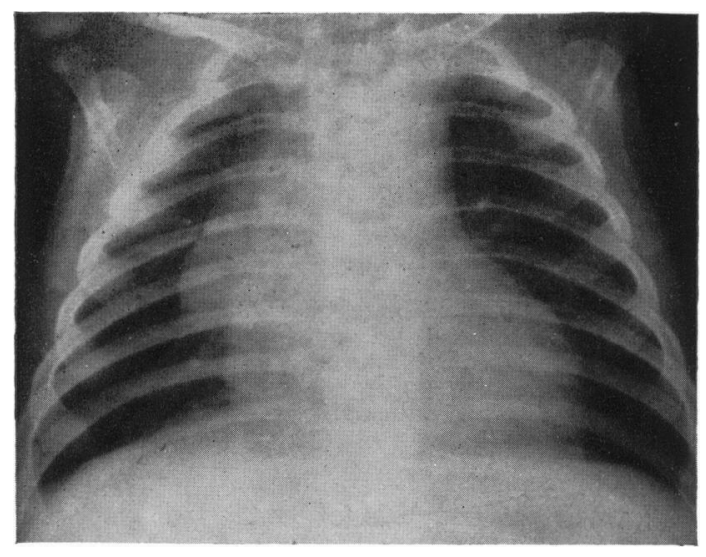

sulphathiazole had little effect. Tuberculin Mantoux test 1 in 1,000 was negative. He is the ninth child, two weeks premature, born normal delivery, weighing $5 \mathrm{lb}$. $14 \mathrm{oz}$. His mother had influenza when three to four months pregnant, with high temperature and cough.

Clinical eXAMination. He was a little backward for his age but otherwise looked normal. There were no abnormal physical signs in the chest.

X-RAY OF THE CHEST (fig. 35 and 36) showed a triangular opacity at the right hilum with straight margins and pointed apex. At one year of age this showed no change, but at seventeen months the opacity had practically disappeared into the mediastinum.

FIG. 31.-Case 13. There is a triangular opacity in the right upper mediastinum. ? Hypoplasia of part of right upper lobe. ? Thymus.
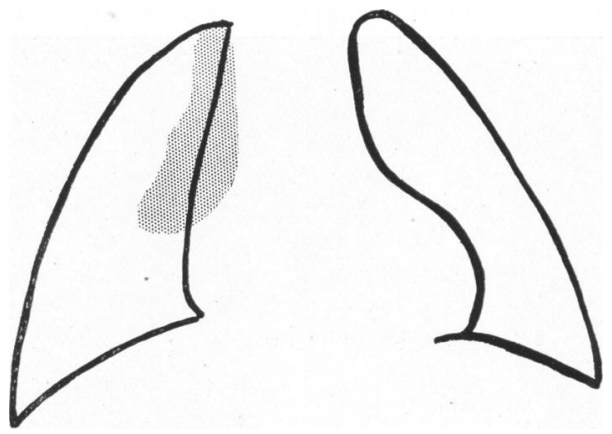

Fig. 32.-Case 13. Diagram of fig. 31 .

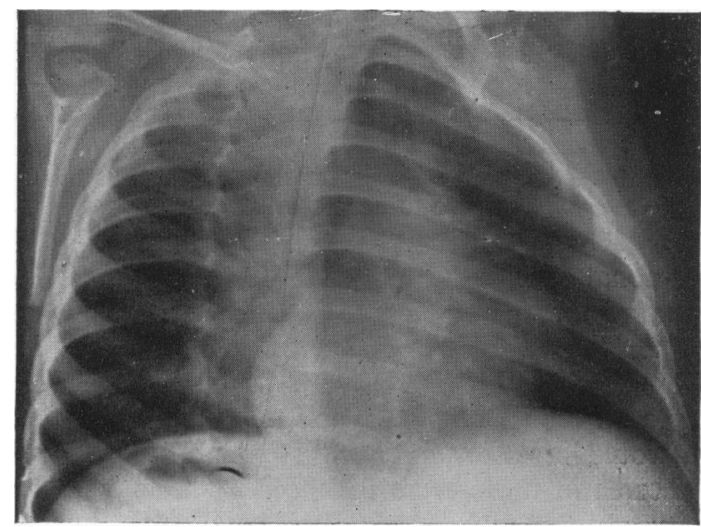

FIG. 33.-Case 13 (right oblique position). The triangular opacity is faintly visible anterior to the cardiac shadow.

Case 14. Keith M., aged eight months, weighing $16 \mathrm{lb} .7 \mathrm{oz}$., was stated to have had some cyanosis for a few weeks after birth. He was then well and free from cough until three months old when he had an attack of wheezing. This had been repeated two or three times since then. On one occasion râles were heard at the right apex. During one of these attacks he ran a temperature up to $102^{\circ} \mathrm{F}$. and respirations rose to 60 per minute; a course of

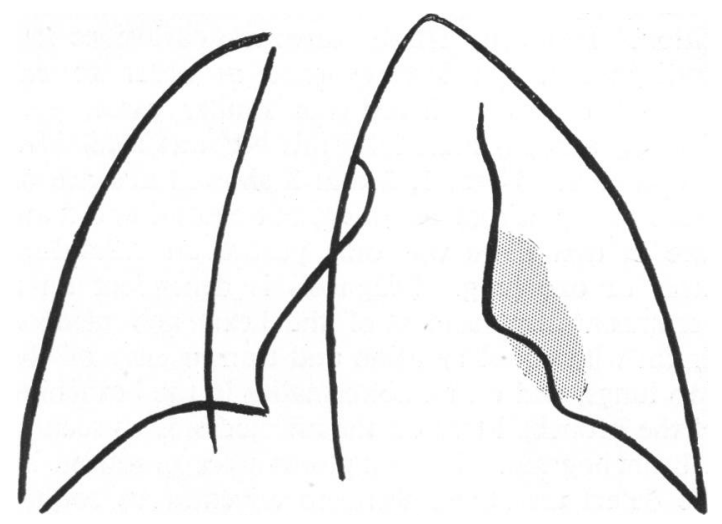

Fig. 34.-Case 13. Diagram of fig. 33.

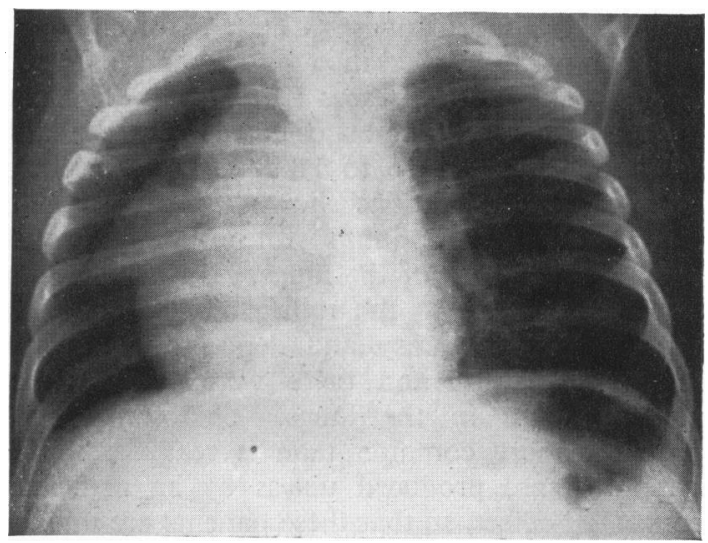

FIG. 35.-Case 14. There is a triangular opacity in the right upper mediastinum. ? Hypoplasia of part of the right upper lobe. ? Thymus.
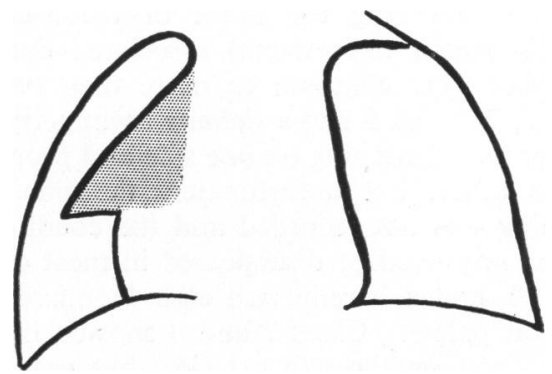

Fig. 36.-Case 14. Diagram of fig. 35 . 
SCREENING OF THE CHEST was unfortunately not done until the age of seventeen months when the opacity could not be defined.

Progress. At the age of seventeen months the child was well, had no cough and was gaining satisfactorily.

\section{Discussion}

The fourteen cases reported here have been recorded because of their rarity, and because diagnosis of maldevelopment of a lung is an important differentiation from atelectasis or pulmonary collapse.

Cases in Group I present a fairly definite diagnosis. In Group II the clinical observation is recorded as such with only suggested explanations of the condition. In Group III the cases are curiosities still undiagnosed, but are recorded in order to encourage others to investigate similar cases, particularly autopsy material if this becomes available.

GrouP I. Cases 1, 2 and 3 showed absence or gross hypoplasia of one lung, but cases 4 and 5 are rare in that there was only partial underdevelopment of one lung. Diagnosis is dependent on a permanent displacement of the heart and mediastinum with equal aeration and translucency of the two lungs, and on an abnormality in the branching of the bronchial tree on the affected side as seen in a bronchogram. No symptoms were produced by the defect and there were no adventitious sounds heard in the chest, as would be expected in a chronic collapse of the lung. All four cases were undersized and cases 1 and 5 showed other multiple congenital abnormalities. Chest deformity with flattening was observed in cases 2,4 and 5 , but the trachea felt central in cases 1,2 and 5 . Screening of the chest was a useful subsidiary investigation.

Group II. Cases 6 to 11 comprise a series of radiological observations showing displacement of the heart and mediastinum with nothing to suggest disease or collapse of the lungs. In five cases the displacement was to the right and in one to the left. The translucency and aeration of the two lungs were equal and there were no abnormal physical signs in the lungs. The condition is probably more common than is realized, as few symptoms are produced unless by an associated congenital defect, so that these patients are unlikely to be x-rayed. In addition, these cases were all diagnosed in the first year of life and the displaced heart and mediastinum gradually returned to normal within two or three years.

Whilst reviewing the notes of these cases, it was discovered that several associated congenital anomalies were common to more than one case. Cases 6, 7, 8 and 9 had a definite asymmetry of the head or face, flattening on one side and prominence on the other, but unfortunately the side of the flattening was not recorded and the condition has by now improved or disappeared in most of them. Case 10 had a harelip and case 11 micrognathia and cleft palate. Cases 7 and 8 showed flattening of the chest on the affected side, but only case 8 had a temporary scoliosis. Case 9 had an asso- ciated congenital short oesophagus. It will be noted that no case was without an associated congenital anomaly of head or face. This is an important observation in view of the well-recorded fact that in agenesis or hypoplasia of a lung there is commonly associated other congenital abnormalities, and cases 1 and 5 of Group I support this observation. Embryological study reveals the fact that the lung bud appears about the same time as the last pharyngeal pouch and is at first closely associated with development of the face and head. It is not unreasonable, therefore, to suggest that in the cases included in Group II there has been a disturbance in early foetal life causing partial arrest of growth on one side of head, face and chest, including the lung which has corrected itself after birth during growth of the child.

Other radiological possibilities must be considered, such as defective posture producing an apparent displacement of the mediastinum, but

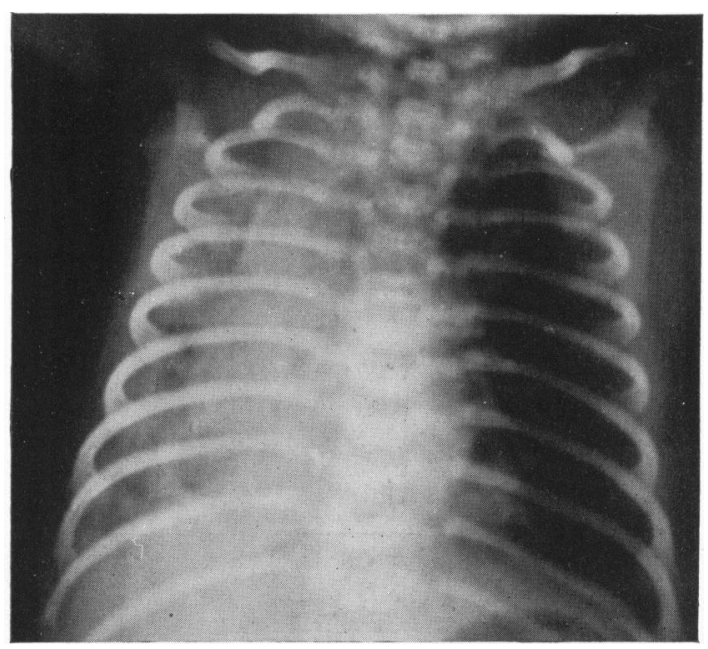

Fig. 37.-Atelectasis of right lung in a new-born baby. Right lung shows loss of translucency.

personal observation whilst screening the child does not support this suggestion. Atelectasis or collapse of the lung would produce loss of translucency and poor aeration (fig. 37) with impaired percussion note on the affected side, and this was not the case. It would have been interesting to see bronchographic pictures in these cases to know whether there was any abnormality of the bronchial tree, but the operation is not without risk in such small infants and it was not felt a justifiable investigation.

Group III. Cases 12, 13 and 14 all presented a triangular shadow in the $\mathrm{x}$-ray situated in the right upper mediastinum anteriorly. In case 12 , this gave the appearance of a collapse of the pectoral portion of the right upper lobe, but there were no symptoms or physical signs suggesting this diagnosis. (In my experience, atelectasis or collapse of a lung due to acquired pulmonary disease usually becomes infected within a year, producing cough, adventitious sounds in the chest and bronchiectasis unless 
re-expansion has occurred.) The bronchograms in case 12 (fig. 19 and 20) suggested that there was no bronchus supplying the opaque area and the phenomena observed on screening the chest make it improbable that air was entering that portion of the lung. In addition, case 12 shows other congenital abnormalities, viz. stenosis of the right bronchus, a small diaphragmatic hernia, and harelip, and case 13 is thought to be mentally backward. During operations on the chest isolated portions of lung tissue have been found in the mediastinum in the region of the lower lobe which did not communicate with a bronchus (personal communication, Dr. L. G. Blair), and it is suggested that the opacities seen in the $\mathrm{X}$-rays of Group III are of this nature. Further observation, with bronchograms and autopsy material, will be necessary to elucidate the problem.

Aetiology. In an attempt to correlate congenital anomalies in the lung with intra-uterine disturbance, a questionnaire was sent to all the mothers of the above patients asking for information on the birth of the child, as well as the occurrence of any illness, accident or haemorrhage during the pregnancy, and if so, at what stage. The answers were interesting.

In Group I, the mother of case 1 had a bad fall when two months pregnant, and the mother of case 4 a slight fall at two months. The mother of case 2 had herpes zoster in the first month of pregnancy.

In Group II, the mother of case 9 had a threatened miscarriage at five months whilst carrying twins, and the mother of case 11 had a miscarriage of the twin at three months; the patient was born at full term but had other congenital abnormalities.

In Group III, the mother of case 12 fell downstairs when two or three months pregnant; and the mother of case 14 had influenza and high temperature and cough at three to four months. Although the questionnaire asked for mishaps during the whole of the period of pregnancy, only such occurrences during the first five months were mentioned in the replies, whilst in Group I the first two months (the period of development of the lung buds) was specifically mentioned. The numbers are too small to permit any conclusions to be made, but these findings justify further research into the relationship of congenital abnormalities with mishaps during pregnancy, comparing the results with a control series.

\section{Summary}

The fourteen cases reported here fall into three categories.

Group I. Five cases of permanent underdevelopment of one lung.

Group II. Six cases of displacement of the heart and mediastinum in the first year of life, correcting itself within two to three years. It is suggested that this may be caused by a temporary hypoplasia of the lung.

Group III. Three cases showing a triangular mediastinal opacity in the $\mathrm{x}$-ray. The possibility of this being caused by an isolated portion of lung tissue with no bronchial communication is discussed.

Thanks are due to Dr. W. G. Wyllie, the Hospital for Sick Children, Great Ormond Street, for permission to study his cases and for much helpful advice and criticism; also to Dr. W. Sheldon for permission to publish case 3 . I am indebted to Dr. M. E. Lund and Dr. M. Ungar for their help whilst working as part-time assistants to the Medical Research Council, also to the Medical Research Council for a grant for expenses.

\section{REFERENCES}

Deweese, E. R., and Howard, J. C. (1944). Radiology, 42, 389 .

Finkelstein, H. (1924). Lehrbuch der Säuglingskrankheiten. Berlin.

Hurwitz, S., and Stephens, H. B. (1937). Amer. J. Med. Sci., 193, 81.

Kiebel, F., and Mall, F. P. (1912). Embryology of the Lung, 2, London.

Killingsworth, W. P., and Hibbs, W. G. (1939). Amer. J. Dis. Child., 58, 571.

Schneider, P. (1912). In Schwalbe, E., Die Morphologie der Missbildungen des Menschen and der Tiere, 3, Pt. 2, 817. Jena.

Schwalbe, E. (1912). Ibid., 763. 